\title{
Relationship of Intravenous Fluid Therapy to Electrolyte Imbalance in Upper Gastrointestinal Surgeries
}

\author{
${ }^{1}$ T. Sudheendra, ${ }^{2}$ Harish Rao.K, ${ }^{3}$ Keshav Prasad Y. V \\ Department of General Surgery KMC, Mangalore
}

\begin{abstract}
Management of Electrolyte imbalance is a known entity in post operative period and a very crucial part in early recovery of post operative patients. There have been studies regarding post operative electrolyte imbalance but the relationship with intravenous fluid (IVF) is not studied in detail. This study basically focuses on the anticipation of electrolyte imbalance and relation with the IVF used. In this study post operative electrolytes specifically in upper Gastrointestinal (GI) surgeries have been considered as there are very few studies dealing specifically with electrolyte imbalance in upper GI surgeries
\end{abstract}

\section{Background}

Management of electrolyte imbalance is a known entity in post operative period and a very crucial part in early recovery of post operative patients. Intravenous fluid administration is an essential part of pre and post operative care and plays an important role in early recovery of patient and reducing the post operative complications associated. All surgical patients are at risk for fluid and electrolyte imbalances. It increases when a patient undergoes intestinal surgery, because of the role of the gastrointestinal system in supplying the body with water and electrolytes. ${ }^{1}$

The surgical literature supports administration of hypertonic fluids, ${ }^{2}$ whereas others recommend only the use of isotonic saline solution, based on data from case series. ${ }^{3}$ Recently, Holliday and coworkers ${ }^{4,5}$ suggested using isotonic fluid in the intra operative and early recovery periods in those patients who cannot tolerate oral intake. This study basically focuses on the anticipation of electrolyte imbalance and relation with the IVF used. In this study post operative electrolytes specifically in upper Gastrointestinal (UGI) surgeries have been considered as there are very few studies dealing specifically with electrolyte imbalance in upper GI surgeries.

\footnotetext{
Aim\& Objectives

-To find out the ideal combination of IVF in post operative management of upper GI surgeries.

-To find the proportion and of postoperative complications of electrolyte imbalance.

-To know the outcome after correcting electrolyte imbalance with appropriate IVF therapy.
}

\section{Methods}

This study is a prospective, observational study which includes 1000 patients all who underwent surgeries of upper GI system in a tertiary care centre from a period of January 2012 to till August 2013 All patients above 18yrs age were included and evaluated pre operatively. Patients with no electrolyte imbalance in pre operative period only were considered for the study. Patients with renal failure, ischemic heart disease, and age less than $18 y$ rs were excluded from the study.

\section{Procedure}

Patients with the above mentioned criteria were monitored for electrolyte imbalances were observed on daily basis till patients were started on orals or weaned off from IVF. Changes in sodium, potassium, chloride and bicarbonate were noted separately. Each of the patient included in the study was followed up to observe IVF given during the post operative period, potassium supplementation grouped separately. This was an observational study only and no interventions were done. However it was not a blind study and the doctors managing these patients were aware of the imbalances which occurred.

\section{Results}

Results were determined by comparing the intravenous fluid given with the electrolyte imbalance on each post operative day. The following table gives overview of the results comparing fluid therapy with electrolyte changes on each post operative day. 
Table 1

\begin{tabular}{|c|c|c|c|}
\hline \multirow[t]{3}{*}{ IV FLUID } & DNS/D5 & 522 & $52.2 \%$ \\
\hline & DNS/NS & 39 & $3.9 \%$ \\
\hline & DNS/RL & 439 & $43.9 \%$ \\
\hline \multicolumn{2}{|l|}{ Total } & 1000 & $100.0 \%$ \\
\hline \multirow{2}{*}{$\begin{array}{l}\text { Potassium } \\
\text { supplement(KCL) }\end{array}$} & $\mathrm{N}^{\#}$ & 273 & $27.3 \%$ \\
\hline & $\mathrm{Y}$ & 727 & $72.7 \%$ \\
\hline \multicolumn{2}{|l|}{ Total } & 1000 & $100.0 \%$ \\
\hline \multirow[t]{2}{*}{ POD $1 \mathrm{Na}$} & $\mathrm{L}$ & 28 & $2.8 \%$ \\
\hline & $\mathrm{N}$ & 972 & $97.2 \%$ \\
\hline \multicolumn{2}{|l|}{ Total } & 1000 & $100.0 \%$ \\
\hline \multirow[t]{2}{*}{ POD $1 \mathrm{~K}$} & $\mathrm{~L}$ & 73 & $7.3 \%$ \\
\hline & $\mathrm{N}$ & 927 & $92.7 \%$ \\
\hline \multicolumn{2}{|l|}{ Total } & 1000 & $100.0 \%$ \\
\hline \multirow[t]{2}{*}{ POD $2 \mathrm{Na}$} & $\mathrm{L}$ & 241 & $24.1 \%$ \\
\hline & $\mathrm{N}$ & 759 & $75.9 \%$ \\
\hline \multicolumn{2}{|l|}{ Total } & 1000 & $100.0 \%$ \\
\hline \multirow[t]{3}{*}{ POD $2 \mathrm{~K}$} & $\mathrm{~L}$ & 666 & $66.6 \%$ \\
\hline & $\mathrm{N}$ & 331 & $33.1 \%$ \\
\hline & $\mathrm{H}$ & 3 & $.3 \%$ \\
\hline \multicolumn{2}{|l|}{ Total } & 1000 & $100.0 \%$ \\
\hline \multirow[t]{3}{*}{ POD $3 \mathrm{Na}$} & $\mathrm{L}$ & 77 & $10.0 \%$ \\
\hline & $\mathrm{N}$ & 687 & $89.5 \%$ \\
\hline & $\mathrm{H}$ & 4 & $.5 \%$ \\
\hline \multicolumn{2}{|l|}{ Total } & 768 & $100.0 \%$ \\
\hline \multirow[t]{3}{*}{ POD $3 \mathrm{~K}$} & $\mathrm{~L}$ & 385 & $50.1 \%$ \\
\hline & $\mathrm{N}$ & 378 & $49.2 \%$ \\
\hline & $\mathrm{H}$ & 5 & $.7 \%$ \\
\hline \multicolumn{2}{|l|}{ Total } & 768 & $100.0 \%$ \\
\hline \multirow[t]{3}{*}{ POD $4 \mathrm{Na}$} & $\mathrm{L}$ & 23 & $3.8 \%$ \\
\hline & $\mathrm{N}$ & 586 & $95.6 \%$ \\
\hline & $\mathrm{H}$ & 4 & $.7 \%$ \\
\hline \multicolumn{2}{|l|}{ Total } & 613 & $100.0 \%$ \\
\hline \multirow[t]{3}{*}{ POD $4 \mathrm{~K}$} & $\mathrm{~L}$ & 148 & $24.1 \%$ \\
\hline & $\mathrm{N}$ & 458 & $74.7 \%$ \\
\hline & $\mathrm{H}$ & 7 & $1.1 \%$ \\
\hline \multicolumn{2}{|l|}{ Total } & 613 & $100.0 \%$ \\
\hline \multirow[t]{3}{*}{ POD $5 \mathrm{Na}$} & $\mathrm{L}$ & 11 & $1.8 \%$ \\
\hline & $\mathrm{N}$ & 582 & $97.5 \%$ \\
\hline & $\mathrm{H}$ & 4 & $.7 \%$ \\
\hline \multicolumn{2}{|l|}{ Total } & 597 & $100.0 \%$ \\
\hline \multirow[t]{3}{*}{ POD $5 \mathrm{~K}$} & $\mathrm{~L}$ & 27 & $4.5 \%$ \\
\hline & $\mathrm{N}$ & 564 & $94.3 \%$ \\
\hline & $\mathrm{H}$ & 7 & $1.2 \%$ \\
\hline \multicolumn{2}{|l|}{ Total } & 598 & $100.0 \%$ \\
\hline
\end{tabular}

Y-Yes, $\mathrm{N}^{\#}$-No, N-normal, L-low, H-high, POD-post operative day .

The following table shows comparison of fluid therapy with imbalances in level of sodium on each post operative day.Table 2 


\begin{tabular}{|c|c|c|c|c|c|c|c|c|c|c|}
\hline & & L & & $\mathrm{N}$ & & $\mathrm{H}$ & & & & \\
\hline IV FLUID & & $\begin{array}{l}\text { No. of } \\
\text { Patients }\end{array}$ & $\%$ & $\begin{array}{l}\text { No. of } \\
\text { Patients }\end{array}$ & $\%$ & $\begin{array}{l}\text { No. of } \\
\text { Patients }\end{array}$ & $\%$ & Total & $\begin{array}{c}\text { Friedman } \\
\text { test value }\end{array}$ & pvalue \\
\hline$\overline{D N S / D 5}$ & POD 1 Na & 14 & $2.7 \%$ & 508 & $97.3 \%$ & 0 & $.0 \%$ & 522 & 317.861 & .000 \\
\hline & $\mathrm{POD} 2 \mathrm{Na}$ & 158 & $30.3 \%$ & 364 & $69.7 \%$ & 0 & $.0 \%$ & 522 & & HS \\
\hline & $\mathrm{POD} 3 \mathrm{Na}$ & 59 & $15.3 \%$ & 326 & $84.7 \%$ & 0 & $.0 \%$ & 385 & & \\
\hline & POD $4 \mathrm{Na}$ & 17 & $5.5 \%$ & 293 & $94.5 \%$ & 0 & $.0 \%$ & 310 & & \\
\hline & POD $5 \mathrm{Na}$ & 9 & $3.0 \%$ & 295 & $97.0 \%$ & 0 & $.0 \%$ & 304 & & \\
\hline DNS/NS & POD $1 \mathrm{Na}$ & 2 & $5.1 \%$ & 37 & $94.9 \%$ & 0 & $.0 \%$ & 39 & 12.649 & .013 \\
\hline & $\mathrm{POD} 2 \mathrm{Na}$ & 8 & $20.5 \%$ & 31 & $79.5 \%$ & 0 & $.0 \%$ & 39 & . & sig \\
\hline & $\mathrm{POD} 3 \mathrm{Na}$ & 7 & $21.9 \%$ & 23 & $71.9 \%$ & 2 & $6.3 \%$ & 32 & . & \\
\hline & POD $4 \mathrm{Na}$ & 5 & $16.7 \%$ & 23 & $76.7 \%$ & 2 & $6.7 \%$ & 30 & . & \\
\hline & POD $5 \mathrm{Na}$ & 2 & $6.7 \%$ & 26 & $86.7 \%$ & 2 & $6.7 \%$ & 30 & & \\
\hline DNS/RL & POD $1 \mathrm{Na}$ & 12 & $2.7 \%$ & 427 & $97.3 \%$ & 0 & $.0 \%$ & 439 & 184.175 & .000 \\
\hline & $\mathrm{POD} 2 \mathrm{Na}$ & 75 & $17.1 \%$ & 364 & $82.9 \%$ & 0 & $.0 \%$ & 439 & & HS \\
\hline & $\mathrm{POD} 3 \mathrm{Na}$ & 11 & $3.1 \%$ & 338 & $96.3 \%$ & 2 & $.6 \%$ & 351 & & \\
\hline & POD $4 \mathrm{Na}$ & 1 & $.4 \%$ & 270 & $98.9 \%$ & 2 & $.7 \%$ & 273 & & \\
\hline & POD $5 \mathrm{Na}$ & 0 & $.0 \%$ & 261 & $99.2 \%$ & 2 & $.8 \%$ & 263 & & \\
\hline
\end{tabular}

POD-post operative day, L-low,N-normal,H-high

Following table shows similar comparison as previous table but with respect to changes in potassium. Table 3

\begin{tabular}{|c|c|c|c|c|c|c|c|c|c|c|}
\hline & & 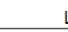 & & 1 & & & & & & \\
\hline IV FLUID & & Count & $\%$ & Count & $\%$ & Count & $\%$ & Total & $\begin{array}{c}\text { Friedman } \\
\text { test value }\end{array}$ & $p$ value \\
\hline DNS/D5 & POD 1 K & 40 & $7.7 \%$ & 482 & $92.3 \%$ & 0 & $.0 \%$ & 522 & 598.623 & .000 \\
\hline & POD $2 \mathrm{~K}$ & 326 & $62.5 \%$ & 196 & $37.5 \%$ & 0 & $.0 \%$ & 522 & & HS \\
\hline & POD $3 \mathrm{~K}$ & 193 & $50.1 \%$ & 192 & $49.9 \%$ & 0 & $.0 \%$ & 385 & & \\
\hline & POD $4 \mathrm{~K}$ & 79 & $25.4 \%$ & 232 & $74.6 \%$ & 0 & $.0 \%$ & 311 & & \\
\hline & POD $5 \mathrm{~K}$ & 12 & $3.9 \%$ & 293 & $96.1 \%$ & 0 & $.0 \%$ & 305 & & \\
\hline DNS/NS & POD $1 \mathrm{~K}$ & 1 & $2.6 \%$ & 38 & $97.4 \%$ & 0 & $.0 \%$ & 39 & 69.408 & .000 \\
\hline & POD $2 \mathrm{~K}$ & 28 & $71.8 \%$ & 11 & $28.2 \%$ & 0 & $.0 \%$ & 39 & & HS \\
\hline & POD $3 \mathrm{~K}$ & 19 & $59.4 \%$ & 13 & $40.6 \%$ & 0 & $.0 \%$ & 32 & & \\
\hline & POD $4 \mathrm{~K}$ & 9 & $30.0 \%$ & 21 & $70.0 \%$ & 0 & $.0 \%$ & 30 & & \\
\hline & POD $5 \mathrm{~K}$ & 1 & $3.3 \%$ & 29 & $96.7 \%$ & 0 & $.0 \%$ & 30 & & \\
\hline DNS/RL & POD $1 \mathrm{~K}$ & 32 & $7.3 \%$ & 407 & $92.7 \%$ & 0 & $.0 \%$ & 439 & 578.299 & .000 \\
\hline & $\mathrm{POD} 2 \mathrm{~K}$ & 312 & $71.1 \%$ & 124 & $28.2 \%$ & 3 & $.7 \%$ & 439 & & HS \\
\hline & POD $3 \mathrm{~K}$ & 173 & $49.3 \%$ & 173 & $49.3 \%$ & 5 & $1.4 \%$ & 351 & & \\
\hline & POD $4 \mathrm{~K}$ & 60 & $22.1 \%$ & 205 & $75.4 \%$ & 7 & $2.6 \%$ & 272 & & \\
\hline & POD $5 \mathrm{~K}$ & 14 & $5.3 \%$ & 242 & $92.0 \%$ & 7 & $2.7 \%$ & 263 & & \\
\hline
\end{tabular}

L-low, N-normal, H-high, HS-highly significant

\section{Discussion}

Table 1 shows the incidence of electrolyte imbalance on each post operative day. As per the study the results show that imbalance in electrolyte levels were maximum on $2^{\text {nd }}$ POD and was more with potassium than sodium. Salt and water retention is normal physiological response of the body in response to surgery, and it has been called as 'sodium retention phase of injury' by Moore'. As per results shown in table 1 initial $48 \mathrm{hrs}$ seem to be very crucial in electrolyte changes in post operative patient. A study done by Drummer et al $^{7}$ was based on observations of the urinary excretion of water and electrolytes and the changes in hormones controlling salt and water homeostasis during the $48 \mathrm{hr}$ after an infusion of $2 \mathrm{~L} 0.9 \%$ saline over $25 \mathrm{~min}$, and after a 48-hr control experiment. It was observed that the rate of electrolyte loss in urine was significantly high during the first 48 hrs after infusion of saline. The incidence of electrolyte abnormalities, one study done on 106 post operative patients shows 4 patients-hypernatremia,3 patients hyperkalemia,27-hypokalemia and 17 hyponatremia ${ }^{8}$. In this study it was found that of the 1000 patients taken in the study on post op day 5 shows hypernatremia in 4 , hyperkalemia 7, hypokalemia 27, hyponatrmia in 11 .

As per statistics shown in table 2, percentage of patients receiving DNS/D5 and DNS/RL show sodium imbalance predominantly on $2^{\text {nd }}$ POD , which as per $p$ value is highly significant. In comparison patients on DNS/NS show changes predominantly on $3^{\text {rd }}$ POD which again is significant. Similarly in table 3 depicts that in all the 3 groups of patients receiving intravenous fluid therapy there is potassium imbalance occurring on $2^{\text {nd }}$ POD which is highly significant. Thr following graph shows the incidence of electrolyte imbalances on each post operative day.

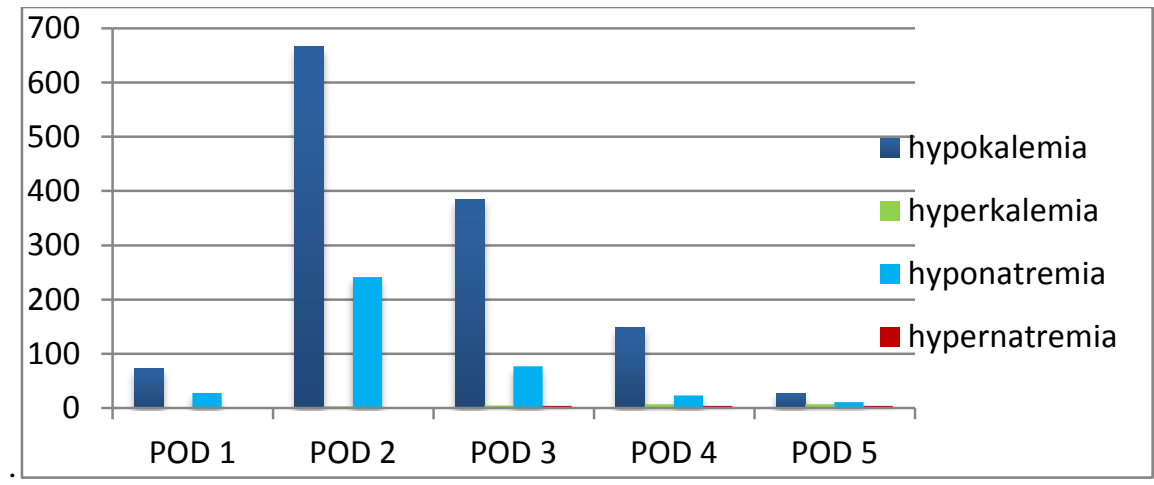


Table 3 shows the division of patients in 3 groups based on intravenous fluid received with or without $\mathrm{KCL}$ and its relation with potassium on each post operative day. In all 3 groups percentage of patients developing potassium imbalance in POD 2 were maximum-in DNS/D5 its is $62.5 \%$, DNS/NS it is $71.8 \%$ and in DNS/RL also it is $71.8 \%$. as per friedman test value these results were found to be significant.

Considering the values on $2^{\text {nd }} P O D$, the study shows patients receiving DNS/D5 with KCL supplements were showing least imbalances irrespective of the surgery they underwent. It shows $16.7 \%$ patients having normal values compared to DNS/RL with $10.2 \%$ and DNS/NS showing $6.7 \%$ patients with normal electrolyte levels. The values found were not significant on day 1 and 3.

In the study patients were also divided based on potassium supplementation. One group did not receive any kind of potassium supplementation. As per the results the values obtained on $2^{\text {nd }}, 4$ th,5th POD were significant which confers that patients receiving KCL supplementation along with DNS/D5 show lesser incidence of electrolyte imbalance with respect to potassium. The values on other post operative days were not significant. The values on $2^{\text {nd }}$ POD patients receiving DNS/D5 showed $83.1 \%$ of patients having hypokalemia in spite of KCL supplementation, whereas it was $93.3 \%$ and $88.9 \%$ for patients receiving DNS/NS and DNS/RL respectively.

The patients were also stratified based on the organs involved in surgeries which shows following fluid therapies showing least incidence of sodium imbalance

\begin{tabular}{|c|c|c|c|c|c|}
\hline \multirow[b]{2}{*}{ Esophagal } & \multicolumn{2}{|c|}{ POD2 } & D3 POD4 & POD5 & \\
\hline & Not Sig. & Not Sig. & Not Sig. & $\mathrm{DNS} / \mathrm{D} 5$ & $\mathrm{DNS} / \mathrm{RL}$ \\
\hline Gastroduodenal & $\mathrm{DNS} / \mathrm{RL}$ & $\mathrm{DNS} / \mathrm{RL}$ & $\mathrm{DNS} / \mathrm{RL}$ & $\mathrm{DNS} / \mathrm{RL}$ & $\mathrm{DNS} / \mathrm{RL}$ \\
\hline Hepatobiliary & DNS/NS & $\mathrm{DNS} / \mathrm{NS}$ & Not Sig. & $\mathrm{DNS} / \mathrm{NS}$ & Not Sig. \\
\hline Pancreatic & Not.Sig & $\mathrm{DNS} / \mathrm{NS}$ & $\mathrm{DNS} / \mathrm{RL}$ & $\mathrm{DNS} / \mathrm{RL}$ & $\mathrm{DNS} / \mathrm{RL}$ \\
\hline
\end{tabular}

\section{Conclusion}

From the data obtained on the observations made during the study it was concluded that in post operative period patient is prone to develop electrolyte imbalances and the incidence is maximum during the second post operative day and the most common imbalance noted was hypokalemia. Hence it is crucial to monitor electrolyte imbalance post operatively especially on second post operative day.

In this study another objective was to determine the appropriate intravenous fluid to anticipate least electrolye imbalances in the post operative period. However from this study this could not be concluded that least electrolyte imbalances are seen when patients receive a combination of DNS/D5 as intravenous fluid therapy, along with KCL correction.

To determine the appropriate intravenous fluid for individual condition which he patient presents with, they were divided into groups based on the organ systems operated. In Esophageal surgeries the relationship with intravenous fluid therapy and electrolyte imbalance was found to be insignificant, hence this group cannot be attributed with one particular fluid therapy. In Hepatobiliary surgeries no definite conclusion could be derived based on the observations as the values were not significant enough to establish a definite regime.

Among the patients undergoing gastroduodenal and pancreatic surgeries it was observed that potassium imbalance least with a combination of DNS/RL, whereas for sodium it was noted that DNS/D5 proved to be a better choice. However definite conclusion to prevent both sodium and potassium imbalance could not be derived, hence it probably can be concluded that patients receiving combination of DNS/D5 with potassium supplementation are expected to have least complications related to electrolyte imbalances

\section{References}

[1]. McConnell EA:Fluid and electrolyte concerns in intestinal surgical procedures.Nurs Clin North Am. 1987 Dec;22(4):853-60.

[2]. Leffen R, Chawls W. Fluid and electrolyte management. In: Oldham K, Colom-bani P, Foglia R, editors. Surgery of Infants and Children. 2nd ed. Philadelphia: Lippincott-Raven; 1997. p 83-115.

[3]. Moritz ML, Ayus JC. Prevention of hospital-acquired hyponatremia: a case for using isotonic saline. Paediatrics 2003;111:227-30.

[4]. Holliday MA, Friedman AL, Segar WE, Chesney R, Finberg L. Acute hospital-induced hyponatremia in children: a physiologic approach. J Pediatr 2004;145:584-7.

[5]. Holliday MA, Segar WE, Friedman A. Reducing errors in fluid therapy management. Paediatrics 2003;111:424-5.

[6]. Moore FD. Metabolic Care of the Surgical Patient. Philadelphia: W.B. Saunders; 1959.

[7]. Drummer C, Gerzer R, Heer $M$ et al. Effects of an acute saline infusion on fluid and electrolyte metab-olism in humans. American Journal of Physiology 1992; 262: F744-F754.

[8]. S.R.Walsh, E.J.Cook et al. Perioperative fluid management Int J Clin Pract, March 2008,62,3,492-497. 